\title{
Traços de personalidade e habilidades sociais em universitários
}

\author{
Daniel Bartholomeu - Faculdade Politécnica de Jundiaî" \\ Carlos Henrique Sancineto da Silva Nunes - Universidade São Francisco ${ }^{2}$ \\ Afonso Antonio Machado - Universidade Estadual Paulista
}

\begin{abstract}
Resumo
O presente estudo teve como objetivo analisar as relações entre habilidades sociais e traços de personalidade englobados por socialização, no modelo dos Cinco Grandes Fatores. O Inventário de Habilidades Sociais (IHS) foi utilizado para a mensuração de habilidades sociais, e para avaliação do nível de socialização foi escolhida a Escala Fatorial de Socialização (EFS). A amostra foi composta por 126 estudantes universitários com média de idade de 21 anos $(\mathrm{DP}=3,37)$, e 53,5\% eram homens. Os resultados da IHS e EFS foram comparados para os sexos, encontrando-se diferenças estatisticamente significativas para seis das dez medidas realizadas no estudo. Foram encontradas correlações significativas entre amabilidade, auto-afirmação e o total do IHS. Pró-sociabilidade correlacionou-se com auto-afirmação e autocontrole. Confiança nas pessoas apresentou correlações significativas com enfrentamento, auto-afirmação e autocontrole. Os resultados indicam que, efetivamente, a personalidade pode influenciar diferentes aspectos da habilidade social.

Palavras-chave: Habilidades sociais; Cinco Grandes Fatores de Personalidade; Socialização; Universitários.
\end{abstract}

\section{Personality traits and social skills in college students}

\begin{abstract}
This study analyzed the relationship between social skills and personality traits, particularly agreeableness trait, based on Big Five model. To assess the social skills, the Social Skills Inventory (Inventário de Habilidades Sociais - IHS) and the Agreeableness Scale (Escala Fatorial de Socialização - EFS) measured agreeableness. The participants were 126 college students with mean age of 21 years old $(S D=3,37), 53,5 \%$ men composed the sample. The sex comparison of the IHS and EFS measures pointed significant differences in six of ten measures. It was ascertain significant correlations between cordiality, coping and assertion and the total score of IHS. Pro-sociability was associated with coping and assertion and self-control. Trust in people was significantly correlated with coping and assertion, expressing positive affection and aggressiveness self-control. This result suggests personality may influence different social skills aspects.

Keywords: Big-Five Factor model; Social skills; College students.
\end{abstract}

\section{Introdução}

O comportamento socialmente competente é definido como aquele que as pessoas consideram apropriado em uma situação específica.

Assim, duas pessoas podem comportar-se de maneiras totalmente diferentes em uma mesma situação, ou a mesma pessoa pode agir de maneiras diferentes em duas situações similares, e tais respostas podem representar o mesmo gran de habilidade social (Caballo, 2003, p. 4).

Nesse contexto, o que determina uma resposta socialmente hábil, muito mais que o comportamento específico, é a sua eficácia ou conseqüência numa dada situação, caracterizando-se por uma conduta eficaz socialmente e não-danosa.

Pesquisas foram realizadas para investigar quais variáveis influenciam e se associam às habilidades sociais, e muitos autores têm indicado que o sexo apresenta um papel fundamental sobre esse construto. Nesse contexto, algumas pesquisas indicaram que mulheres manifestaram uma maior quantidade de sentimentos positivos, enquanto os homens, a seu turno, tiveram dificuldades de expressar sentimentos negativos e fazer pedidos, além de serem mais assertivos em situação de trabalho (Gambrill \& Richey, 1975; Hollandswort \& Wall , 1977).

Também, Eisler, Hersen, Miller e Blanchard (1975) verificaram diferenças em pacientes psiquiátricos homens quando interagiam com pessoas do mesmo sexo e

Endereço para correspondência:

Universidade São Francisco - Rua Alexandre Rodrigues Barbosa, 45 - 13251-900 - Itatiba-SP

${ }^{1}$ E-mail: d_bartholomeu@yahoo.com.brou daniel.bartholomeu@am.unisal.br

${ }^{2}$ E-mail: carloshnunes@mac.com 
do sexo oposto, indicando uma maior quantidade de condutas socialmente hábeis quando dirigidas a mulheres, tais como falar mais tempo, elogiar e manifestar apreço, indicar mudança de comportamento, dentre outras. Em consonância, Hess (1975) salientou que as diferenças perceptivas dos efeitos do sexo nas habilidades sociais são decorrentes das expectativas dos papéis sociais, da influência do sexo do outro nas avaliações e emissões de respostas sociais. Certos trabalhos da literatura relataram diferenças nas habilidades sociais e socialização, um componente da personalidade, em função do sexo, indicando que as mulheres apresentam níveis de socialização mais elevados em detrimento dos homens (Nunes \& Hutz, 2007a).

Rose e Tryon (1979) também indicaram que as condutas assertivas femininas tendem a ser vistas como mais agressivas do que as masculinas. Vale mencionar que a investigação das relações do comportamento social com o sexo segue sendo um tema controvertido na literatura, uma vez que certos autores não identificaram tais diferenças (Schroeder \& Rakos, 1983).

Outros autores investigam os fatores que podem influenciar $o$ desenvolvimento e manutenção das habilidades sociais. Bellack e Morrison (1982) indicam que, para se manter as condutas socialmente hábeis, deve-se estar em constante aprendizado, uma vez que os costumes, moda e linguagem se alteram no curso da vida. Assim, o desuso pode provocar a perda das habilidades sociais, bem como dificuldades cognitivas ou afetivas. Desse fato, radica que as respostas sociais seriam aprendidas e manifestas em distintas formas (verbais e não-verbais). Essas condutas nortearam a delimitação de dimensões do comportamento socialmente hábil.

Um dos primeiros autores a propor essas categorias foi Lazarus (1973), que sugeriu quatro tipos de respostas hábeis socialmente (na época, eram definidos como comportamentos assertivos), quais sejam, a capacidade de dizer não; de pedir favores e fazer pedidos; de expressar sentimentos positivos e negativos; e de iniciar, manter e terminar conversações. Desde então, outras categorias de resposta foram propostas, como fazer elogios, aceitar pedidos, falar em público, etc. (Rathus, 1975).

Tais indicadores são freqüentemente utilizados para pesquisas envolvendo habilidades sociais e instrumentos foram desenvolvidos para a sua mensuração. No Brasil, o Inventário de Habilidades Sociais foi desenvolvido e validado por Del Prette e Del Prette (2001), tendo em vistas esses aspectos mencionados na literatura.

Para identificar a estrutura interna do Inventário de Habilidades Sociais (IHS), os autores realizaram uma análise fatorial utilizando método de extração de fatores alfa e rotação varimax, fornecendo uma solução de cinco fatores que explicaram $92,75 \%$ de variância. $O$ fator 1 recebeu a denominação de enfrentamento com risco, retratando situações de relacionamento interpessoal em que se afirma defesa de direitos e de auto-estima, em outros termos, avaliam o conceito de assertividade, com risco potencial de reação indesejável por parte do interlocutor. Indica ainda o controle da ansiedade em situações como se apresentar a pessoas desconhecidas, discordar de autoridade, falar em público, entre outras. As condutas no fator 2 , denominado auto-afirmação na expressão de afeto positivo, referem-se à expressão de afetos positivos e de afirmação da autoestima, não envolvendo risco interpessoal ou um risco mínimo de reação indesejável. Entre as condutas estão elogiar familiares, expressar sentimento positivo, defender uma outra pessoa num grupo, dentre outras. Por sua vez, o terceiro fator, conversação e desenvoltura social, abrange situações sociais neutras que demandam traquejo social na conversação. Altos escores nesse fator supõem um bom conhecimento de normas de relacionamento para o desempenho de habilidades como manter e encerrar uma conversação, encerrar conversas ao telefone, reagir a elogios, abordar autoridades, recusar pedidos, entre outras. O quarto fator, denominado auto-exposição a desconbecidos on a situaçoes novas, informa sobre a abordagem de pessoas desconhecidas, sendo parte semelhante à dimensão anterior, mas com um risco maior de reação do outro. Nas avaliações, implica fazer apresentações em público, pedir favores e fazer perguntas à desconhecidos. Finalmente, o quinto fator corresponde ao autocontrole da agressividade em situaçoes aversivas e reúne itens que supõem reação a estimulações aversivas que demandam controle da agressividade e raiva. Implica expressar desagrado ou raiva de forma mais competente socialmente, em termos do controle de seus sentimentos negativos. Abrange habilidades de lidar com críticas dos pais e brincadeiras ofensivas, tendo ainda um componente de impulsividade que é incompatível com a calma e autocontrole avaliado neste fator (Del Prette, Del Prette \& Barreto, 1998). A consistência interna por alfa de Cronbach para esses fatores forneceu índices entre 0,74 e 0,97 .

Outros estudos de validade para esse teste foram feitos e merecem destaque. Dentre eles, Del Prette, Del Prette e Barreto (1999) estudaram grupos controle e experimental num pré e pós-teste com um procedimento de intervenção que visou ao desenvolvimento interpessoal, evidenciando diferenças no grupo experimental quanto aos escores do IHS-Del-Prette.

\section{Habilidades sociais e personalidade}

A avaliação das habilidades sociais, via de regra, é calcada nas situações de interação social. Embora seja relevante estudar as condutas que produzem uma melhor interação, não se pode perder de vista que os tipos de 
interações que as pessoas estabelecem são modulados por certos componentes da personalidade e podem favorecer o estabelecimento de um melhor ou pior padrão de interações sociais, uma vez que informam as maneiras peculiares de um indivíduo comportar-se socialmente. Da mesma forma, as gratificações e frustrações que a pessoa obtém a partir do contato com as outras também podem afetar a organização de sua personalidade. Ao lado disso, compreender as concomitâncias peculiares existentes entre essas variáveis pode auxiliar o planejamento de intervenções nessa área (Bueno, Oliveira \& Oliveira, 2001).

Em uma revisão da literatura, observou-se que a maior parte das pesquisas que trabalharam com essas duas variáveis as avaliaram separadamente, geralmente em relação a outras variáveis. Exemplo disso é o estudo de Reis, Wheeler, Kernis, Spiegel \& Nezlek (1985), que tomaram medidas de habilidades sociais, confiança, orientação sexual, auto-estima, solidão e as relacionaram aos problemas de saúde de estudantes universitários, partindo do pressuposto que pessoas com problemas de saúde teriam interações sociais mais pobres. Seus resultados confirmaram essa hipótese somente para as mulheres.

O trabalho de Schill (1995) examinou as relações entre tendências pessimistas, associadas à personalidade (como o sentimento de derrota) e habilidades sociais em estudantes universitários. Seus resultados apontaram que pessoas mais negativistas tendem a apresentar menos habilidades sociais, empatia e necessidade de aprovação social. Paralelamente, autores como Penn e Mueser (1995) ressaltam que várias características de personalidade estão envolvidas nas habilidades sociais, já que desordens de personalidade tendem a afetá-las, enquanto características positivas como auto-estima tendem a ser típicas de sujeitos mais expressivos no trato social, tendo mais credibilidade com os outros do que indivíduos com ansiedade social.

De particular importância para o presente estudo foi o trabalho de Bueno, Oliveira e Oliveira (2001), que buscou correlações entre habilidades sociais, avaliado pelo IHS-Del Prette, e traços de personalidade no modelo dos Cinco Grandes Fatores, avaliados por meio de uma lista de adjetivos descritores da personalidade compilados por Hutz e colaboradores (1998), hipotetizando que as diferentes habilidades sociais seriam explicadas pelos traços de personalidade. Os descritores de traço foram aplicados juntamente com o IHS em estudantes universitários brasileiros e foi verificada a sua correlação. Dentre os resultados, identificou-se que o fator enfrentamento com risco do IHS correlacionou-se significativamente à extroversão e abertura para novas experiências; o fator auto-afirmação na expressão de afetos positivos com socialização e equilibrio emocional. Por sua vez, o fator auto-exposição a desconhecidos e a situações novas relacionou-se à extroversão e estabilidade emocional.
Finalmente, o fator autocontrole da agressividade relacionou-se à socialização.

Além das evidências empíricas que apóiam a hipótese da associação entre os componentes de habilidade social e os fatores de personalidade no modelo dos CGF, uma análise detalhada das definições de seus construtos aponta uma evidente interface entre eles. Tal avaliação indica que vários fatores da personalidade podem ser importantes para a explicação de HS, mas principalmente socialização apresenta características comuns a esse construto.

Socialização é um importante componente da personalidade humana que, no modelo dos Cinco Grandes Fatores, descreve a qualidade das relações interpessoais dos indivíduos (Digman, 1990; Nunes \& Hutz, 2002). O fator relaciona-se aos tipos de interações que uma pessoa apresenta ao longo de um contínuo que se estende da compaixão ao antagonismo. As tendências apontadas para pessoas com altas pontuações nesse fator são agradabilidade social, amabilidade, altruísmo, cuidado com os demais, amor e apoio emocional. São normalmente generosas, bondosas, afáveis, prestativas e altruístas. Ávidas para ajudar aos outros, apresentam ainda tendência a ser responsivas e empáticas, e acreditam que a maioria das outras pessoas irá agir da mesma forma. Por sua vez, pessoas com baixos escores em socialização seriam descritas como cínicas, não-cooperativas e irritáveis, podendo também ser manipuladoras, vingativas $\mathrm{e}$ implacáveis. Caracterizam-se ainda por hostilidade, indiferença aos demais, egoísmo e inveja.

Vários estudos têm mostrado a importância e a aplicabilidade das escalas CGF no diagnóstico clínico. Por exemplo, há indicações claras na literatura de que pessoas com diagnóstico de transtorno de personalidade anti-social apresentam baixos escores de socialização (Widiger, Trull, Clarkin, Sanderson \& Costa, 2002). Tal aspecto é relevante, uma vez que, conforme já mencionado, transtornos da personalidade podem afetar HS de forma significativa.

Há que se considerar, ainda, que alguns pesquisadores que trabalham com a avaliação de habilidades sociais tendem a tomar a socialização como um dos indicadores da competência social ou mesmo como critério para a avaliação do progresso de pessoas inicialmente com baixos índices de habilidades sociais submetidas a procedimentos de intervenção em tais aspectos (Kontos, Hsu \& Dunn, 1994; Facto \& Schilmoeller, 1983). Nesse sentido, seria esperado encontrar associações entre essas variáveis.

Ao mesmo tempo, o trabalho de Bueno, Oliveira e Oliveira (2001) evidenciou que certas habilidades sociais são explicadas pelo fator socialização. No entanto, o instrumento utilizado neste estudo, o conjunto de descritores de traço para avaliação dos CGF, é uma medida 
apenas dos fatores gerais e não permite a mensuração de suas facetas. Assim, entendendo que há uma associação socialização e habilidades sociais, torna-se notório o seu maior detalhamento, e tal processo torna-se possível com a utilização de instrumentos que podem avaliar este fator da personalidade considerando os seus componentes.

Tendo em vista essas considerações, o presente trabalho pretende aprofundar o estudo das associações entre socialização e habilidades sociais, utilizando a Escala Fatorial de Socialização, desenvolvida por Nunes e Hutz (2007b) que avalia esse fator em três dimensões, a saber, amabilidade, pró-sociabilidade e confiança nas pessoas.

\section{Método}

\section{Participantes}

Participaram desta pesquisa 126 estudantes universitários de uma instituição de ensino particular de uma cidade do interior do estado de São Paulo que cursavam educação física. A média de idade na amostra foi 21 anos ( $\mathrm{DP}=3,37)$, com pessoas de 18 até 35 anos, sendo $68,3 \%$ dos indivíduos de até 21 anos. Em relação ao sexo, observou-se uma prevalência de homens (53,5\%), embora a distribuição tenha sido quase a mesma. Cerca de $93 \%$ dos indivíduos eram solteiros e 41,7\% só estudavam.

\section{Instrumentos}

1 - Inventário de Habilidades Sociais - IHS-Del-Prette (Del Prette \& Del Prette, 2001)

Este instrumento apresenta 38 itens que descrevem situações de interação social e as pessoas são solicitadas a avaliar a freqüência de ocorrência em uma escala de cinco pontos (variando de nunca a sempre). Os escores do fator enfrentamento com risco (com 11 itens) podem variar de 11 a 55. O fator auto-afirmação na expressão de afeto positivo, com 7 itens, tem pontuações que podem variar de 7 a $35 . \mathrm{Na}$ terceira dimensão, conversação e desenvoltura social, com 7 itens, a pontuação pode variar de 7 a 35 . O quarto fator, autoexposição a desconhecidos ou a situações novas, tem 4 itens e seus escores podem variar de 4 a 20 . Finalmente, na dimensão autocontrole da agressividade a situações aversivas, os escores vão de 3 a 15, já que apresenta 3 itens.

As propriedades psicométricas ora apresentadas indicam a adequação desse intrumento na avaliação das habilidades sociais em universitários. Seus bons resultados habilitam essa escala para o uso em pesquisas.

2 - Escala Fatorial de Socialização (Nunes \& Hutz, 2007b)

A EFS é uma escala objetiva, composta por 70 itens de auto-relato, que avaliam socialização no modelo dos Cinco Grandes Fatores de Personalidade. As respostas são dadas a partir de uma escala tipo Likert de 7 pontos, ancorada nas extremidades, que variam de discordo completamente até concordo completamente. A EFS é composta por três facetas, denominadas amabilidade (S1), prósociabilidade (S2) e confiança nas pessoas (S3), que são avaliadas, respectivamente, por 33, 23 e 14 itens.

Amabilidade agrupa itens que descrevem o quão atenciosas, compreensivas e empáticas as pessoas procuram ser com as demais. Além disso, indica o quão agradáveis as pessoas buscam ser com os outros, observando suas opiniões, sendo educadas com elas e se importando com as suas necessidades. Pessoas altas em amabilidade tendem a ser atenciosas com as demais, demonstrando sua preocupação com as necessidades alheias. Tendem a ser proativas para resolver os problemas das pessoas, bem como expor seu apreço por elas. Altos em amabilidade apresentam uma preocupação em tratar bem as demais pessoas, perguntando como estão e esforçando-se para que sintam-se bem (Nunes \& Hutz, 2007b).

Pró-sociabilidade agrupa itens que descrevem comportamentos de risco, concordância ou confronto com leis e regras sociais, moralidade, auto e heteroagressividade e padrões de consumo de bebidas alcoólicas. Pessoas com altos resultados em pró-sociabilidade tendem a evitar situações de risco, bem como atitudes consideradas transgressoras a leis ou regras sociais. Tendem a apresentar uma postura franca com os demais, evitando pressioná-los ou induzi-las. Pessoas com baixos resultados em prósociabilidade podem ser manipuladoras, agindo ativamente para que as demais pessoas façam o que desejam. Podem apresentar um padrão hostil de interação com os demais, tratando-os de forma desrespeitosa ou opositora. Podem apresentar um padrão elevado de consumo de álcool, o que pode potencializar as situações de risco às quais se expõem (Nunes \& Hutz, 2007b).

Confiança nas pessoas agrupa itens que descrevem o quanto as pessoas confiam nos demais e acreditam que eles não as prejudicarão. Pessoas com altos escores em confiança tendem a apresentar uma disposição a acreditar que os outros são honestos e bem-intencionados. Casos com baixos escores nessa escala tendem a ser céticos e assumem que os outros podem ser desonestos ou perigosos.

A validação de construto da EFS (Nunes \& Hutz, 2007b) foi realizada com uma amostra composta por pessoas provenientes de cinco estados brasileiros, com idade média de 21,4 anos ( $D P=5,84)$. Foram realizadas análises fatoriais para a verificação da dimensionalidade da EFS, tendo os fatores S1, S2 e S3 apresentado consistência interna, calculada por alfa de Cronbach, de 0,91; 0,84 e 0,80 , respectivamente. A escala geral apresentou uma consistência interna de 0,92 . 
Nunes, Nunes e Hutz (2006) realizaram um estudo para verificação da validade de critério da EFS em dois grupos, um composto por 34 estudantes universitários e outro com 41 pessoas que apresentavam indicadores de transtorno da personalidade anti-social. Uma regressão logística foi realizada para verificar o poder preditivo da EFS aplicada conjuntamente com uma entrevista semiestruturada para a identificação dos grupos. Com essa análise, foi verificado que a utilização combinada dessas técnicas gerou um modelo com sensibilidade de $87,8 \%$ e especificidade de $90,9 \%$, ou seja, foi possível identificar, em grande parte, em que grupo as pessoas estavam alocadas.

\section{Procedimento}

Os instrumentos foram aplicados coletivamente em sala de aula após o consentimento dos professores e da direção da escola. A participação no estudo foi voluntária e não houve nenhum pagamento ou outras formas de indução para os participantes.

Foi solicitada aos participantes deste estudo a assinatura do Termo de Consentimento Informado, obedecendo às regras de conduta ética na pesquisa com seres humanos. Todas as medidas necessárias para assegurar o sigilo e a confidencialidade dos dados foram tomadas. Não houve seleção dos estudantes em relação ao semestre que estavam cursando. As escalas foram aplicadas conforme as instruções presentes em seus manuais técnicos.

\section{Análise dos dados e resultados}

O levantamento dos resultados da EFS e IHS foi realizado conforme os procedimentos descritos no seu manual técnico. Para comparar os resultados da amostra do presente estudo com os grupos normativos do IHS e EFS, foi calculado o escore $Z$ dos participantes, considerando-se a média e desvio padrão apresentados pela amostra normativa em função do sexo. Posteriormente, as médias dos escores encontrados na amostra do presente estudo foram comparadas às do grupo normativo a partir da realização de testes $\mathrm{t}$ de Student. A média dos escores brutos, o desvio padrão e resultado dos testes $\mathrm{t}$ são apresentados na Tabela 1.

Foram encontradas diferenças estatisticamente significativas para todas as medidas de socialização comparadas. Tais resultados indicam que a amostra avaliada no presente estudo apresentou níveis mais reduzidos de socialização do que a amostra normativa da EFS para todas as suas facetas. No entanto, é importante notar que as diferenças encontradas, calculadas pela fórmula do tamanho do efeito (d), apesar de estatisticamente significativas, ficaram na ordem de aproximadamente $1 / 3$ do desvio padrão observado no grupo normativo, ou seja, não podem ser consideradas muito elevadas.

Análises semelhantes, realizadas com os resultados do IHS, indicaram que a amostra do presente estudo apresentou médias mais altas do que o grupo normativo para Conversação e desenvoltura social e autoexposição a desconhecidos e situações novas. No entanto, o tamanho do efeito encontrado também não foi alto, sendo inferior a 0,4 desvios padrão. Os resultados dessas análises indicam que, apesar de terem sido encontradas diferenças nos escores da amostra em algumas medidas utilizadas no estudo, elas foram moderadas. Além disso, a variância encontrada nas medidas foi razoavelmente ampla, próxima à encontrada nos estudos de normatização, o que indica a viabilidade de estudos correlacionais com os instrumentos. Vale lembrar que a realização de estudos correlacionais com amostras que apresentem variância muito reduzida pode acarretar a sua subestimação.

Tabela 1 - Média e desvio padrão dos escores $\mathrm{Z}$ e resultados dos testes $\mathrm{t}(\mathrm{n}=126)$

\begin{tabular}{lccccc}
\hline Escala & Média & Desvio padrão & $\mathrm{t}$ & $\mathrm{gl}$ & $\mathrm{p}$ \\
\hline \multicolumn{7}{c}{ Inventário de Habilidades Sociais } \\
Enfrentamento e auto-afirmação com risco & 0,19 & 0,99 & 1,897 & 592 & $\mathrm{NS}$ \\
Auto-afirmação na expressão de sentimento positivo & 0,18 & 0,90 & 1,831 & 592 & $\mathrm{NS}$ \\
Conversação e desenvoltura social & 0,39 & 1,22 & 3,700 & 592 & $<0,001$ \\
Auto-exposição a desconhecidos e situações novas & 0,28 & 0,92 & 2,83 & 592 & $<0,001$ \\
Autocontrole da agressividade & 0,11 & 0,76 & 1,342 & 592 & NS \\
\hline \multicolumn{7}{c}{ Escala Fatorial de Socialização } \\
Amabilidade & $-0,33$ & 0,89 & 3,89 & 1224 & $<0,001$ \\
Pró-sociabilidade & $-0,38$ & 0,92 & 4,351 & 1224 & $<0,001$ \\
Confiança & $-0,19$ & 0,87 & 2,285 & 1224 & $<0,001$ \\
Total EFS & $-0,37$ & 0,82 & 4,682 & 1224 & $<0,001$ \\
\hline
\end{tabular}


Para verificar as associações entre a idade dos respondentes e os resultados do IHS e da EFS, foi verificada correlação entre essas variáveis, a partir do coeficiente de correlação produto-momento de Pearson. Não foram encontradas correlações significativas para nenhuma subescala dos instrumentos utilizados, nem para seus escores totais. Foi verificado se havia diferenças nas medidas dos instrumentos em relação ao sexo dos respondentes. Para isso, valeu-se da prova t de Student, e esses dados estão na Tabela 2. Vale notar que os graus de liberdade apresentados na Tabela 2 são os mesmos da Tabela 1, uma vez que as amostras usadas para as análises foram as mesmas.

Tabela 2 - Média, desvio padrão, mínimo, máximo e resultados dos testes t de IHS e EFS ( $\mathrm{n}=126$ )

\begin{tabular}{|c|c|c|c|c|c|c|c|c|}
\hline \multirow{2}{*}{ Escala } & \multicolumn{2}{|c|}{ Média } & \multicolumn{2}{|c|}{ Desvio padrão } & \multirow[b]{2}{*}{ Mín. } & \multirow[b]{2}{*}{ Max. } & \multirow[b]{2}{*}{$\mathrm{t}$} & \multirow[b]{2}{*}{$\mathrm{p}$} \\
\hline & Homem & Mulher & Homem & Mulher & & & & \\
\hline \multicolumn{9}{|c|}{ Inventário de Habilidades Sociais } \\
\hline Enfrentamento e auto-afirmação com risco & 10,55 & 9,82 & 3,02 & 2,73 & 2,51 & 15,87 & $-1,39$ & $\mathrm{NS}$ \\
\hline $\begin{array}{l}\text { Auto-afirmação na expressão de } \\
\text { sentimento positivo }\end{array}$ & 8,83 & 9,56 & 1,83 & 1,33 & 2,54 & 11,70 & 2,59 & $<0,01$ \\
\hline Conversação e desenvoltura social & 7,06 & 7,23 & 1,63 & 1,75 & 2,90 & 11,02 & 0,55 & NS \\
\hline $\begin{array}{l}\text { Auto-exposição a desconhecidos e } \\
\text { situações novas }\end{array}$ & 3,38 & 3,96 & 1,21 & 1,02 & 0,00 & 5,82 & 2,85 & $<0,01$ \\
\hline Autocontrole da agressividade & 1,36 & 0,89 & 0,63 & 0,66 & $-0,68$ & 2,86 & $-4,03$ & $<0,001$ \\
\hline Total IHS & 98,25 & 99,41 & 14,34 & 13,86 & 61,00 & 132,00 & 0,20 & NS \\
\hline \multicolumn{9}{|c|}{ Escala Fatorial de Socialização } \\
\hline Amabilidade & 5,41 & 5,62 & 0,68 & 0,60 & 3,88 & 6,91 & 1,84 & $<0,05$ \\
\hline Pró-sociabilidade & 5,03 & 5,60 & 0,73 & 0,73 & 2,65 & 6,87 & 4,31 & $<0,001$ \\
\hline Confiança & 4,60 & 4,80 & 0,96 & 0,68 & $-0,57$ & 6,21 & 1,30 & NS \\
\hline Total EFS & 15,04 & 16,02 & 1,67 & 1,47 & 9,36 & 18,93 & 3,37 & 0,001 \\
\hline
\end{tabular}

Os resultados dessa análise evidenciaram que seis das 10 medidas efetuadas apresentaram diferenças de média estatisticamente significativas em função do sexo dos respondentes. Nesse contexto, as pontuações de prósociabilidade, socialização total, auto-afirmação na expressão de sentimento positivo e auto-exposição a desconhecidos e situações novas apresentaram médias maiores para as mulheres em detrimento dos homens. Somente a média do escore de autocontrole da agressividade foi maior no sexo masculino. Tendo em vista esses dados, optou-se por separar as análises correlacionais em razão do sexo.

Nesses termos, estudou-se a associação entre os fatores de cada uma das escalas dos instrumentos por meio da correlação produto-momento de Pearson, estabelecendo-se o nível de significância de 0,05 . Os resultados dessa análise no geral estão na Tabela 3.

Tabela 3 - Coeficientes de correlação produto-momento de Pearson entre as variáveis do IHS e EFS

\begin{tabular}{|c|c|c|c|c|c|c|c|c|c|c|c|c|}
\hline & \multicolumn{3}{|c|}{ Amabilidade } & \multicolumn{3}{|c|}{ Pró-sociabilidade } & \multicolumn{3}{|c|}{ Conf. nas pessoas } & \multicolumn{3}{|c|}{ Total socialização } \\
\hline & $\mathrm{T}$ & $\mathrm{H}$ & M & $\mathrm{T}$ & $\mathrm{H}$ & M & $\mathrm{T}$ & $\mathrm{H}$ & M & $\mathrm{T}$ & $\mathrm{H}$ & $\mathrm{M}$ \\
\hline $\begin{array}{l}\text { Enfrentamento e auto- } \\
\text { afirmação com risco }\end{array}$ & 0,11 & & & $-0,21 *$ & & $-0,34^{*}$ &,$- 20^{*}$ & & $-0,28^{*}$ & $-0,18$ & & \\
\hline $\begin{array}{l}\text { Auto-afirmação na } \\
\text { expressão de sentimento } \\
\text { positivo }\end{array}$ & $0,34^{* *}$ & $0,41^{* *}$ & & 0,17 & & & $0,21 *$ & & & $0,30^{* *}$ & $0,29 *$ & \\
\hline $\begin{array}{l}\text { Conversação e desenvoltura } \\
\text { social }\end{array}$ & 0,02 & & & 0,06 & & & $-0,12$ & & & 0,01 & & \\
\hline $\begin{array}{l}\text { Auto-exposição a } \\
\text { desconhecidos e situações } \\
\text { novas }\end{array}$ & 0,09 & & & 0,09 & & & $-0,11$ & & & 0,02 & & \\
\hline $\begin{array}{l}\text { Autocontrole da } \\
\text { agressividade }\end{array}$ & $-0,05$ & & & $0,32 * *$ & $0,48^{* *}$ & $0,53^{* *}$ & $0,21 *$ & & $0,43 * *$ & $0,25 * *$ & $0,30^{*}$ & $0,49^{*}$ \\
\hline Total IHS & $0,24^{* *}$ & & & 0,03 & & & $-0,04$ & & & 0,08 & & \\
\hline
\end{tabular}


Dentre os dados obtidos por essa análise, evidenciaram-se correlações positivas e significativas entre o fator auto-afirmação na expressão de sentimento positivo e amabilidade, confiança nas pessoas e o total de socialização. Assim, pode-se referir que quanto mais os universitários tendem a expressar afetos positivos e afirmar sua auto-estima, mais são preocupados e altruístas, com desejo de ajudar os demais, compreensivos, atenciosos e empáticos, sendo mais agradáveis com os demais, esforçando-se para que esses sintam-se bem, confiando nas pessoas e não acreditando que estas os possam prejudicar.

A seu turno, o fator enfrentamento e autoafirmação com risco correlacionou-se negativa $e$ significativamente com pró-sociabilidade e confiança nas pessoas, apesar de seus coeficientes terem sido baixos, indicando pouca variabilidade comum entre essas variáveis. Essa tendência, embora fraca, pode ser interpretada como: quanto mais as pessoas são caracterizadas pela confiança nos demais, acreditando que esses não os tentarão enganar ou prejudicar, evitando situações de risco ou atitudes que ferem alguma lei ou regra social, menos tendem a se afirmar em defesa de seus direitos e de sua auto-estima, sendo menos assertivas.

Por sua vez, o fator autocontrole da agressividade associou-se significativa e positivamente com pró-sociabilidade, confiança nas pessoas e total de socialização com coeficientes baixos. Esses resultados sugerem que pessoas com maior controle de agressividade e raiva em situações aversivas são caracterizadas por confiança nos demais e lealdade com as pessoas, além de acreditarem que as pessoas são honestas e bem-intencionadas. Além disso, tendem a evitar situações em que se coloquem ou aos outros em risco, evitam situações de embate com os outros e tendem a ser mais cuidadosos com leis e regras sociais. Finalmente, o escore total do IHS correlacionou-se somente a amabilidade com coeficientes positivos e significativos, o que indica que, no geral, quanto mais habilidade social os universitários demonstram, mais tendem a ser atenciosos, compreensivos e empáticos com os demais, sendo agradáveis com os outros, observando suas opiniões e importando-se com suas necessidades.

Foi realizada ainda uma análise suplementar, na qual foram calculadas as correlações entre as medidas da EFS e IHS separadamente por sexo. Foram observadas situações em que houve correlações significativas e com magnitudes médias apenas para um sexo, indicando que as associações entre os construtos mensurados pelo IHS e EFS não seguiam o mesmo padrão em relação ao sexo dos respondentes. Tal situação ocorreu entre amabilidade e autoafirmação na expressão de sentimento positivo, em que foi encontrada uma correlação positiva e significativa $(\mathrm{r}=0,41 ; \mathrm{p}<0,01)$ apenas para homens. Houve duas ocorrências desse tipo com a correlação entre confiança nas pessoas, enfrentamento e auto-afirmação com risco $(r=-0,28 ; \quad \mathrm{p}<0,05)$ e autocontrole da agressividade $(\mathrm{r}=0,43 ; \mathrm{p}<0,05)$, nas quais foram encontradas correlações significativas apenas para as mulheres.

Tais resultados indicam que não apenas homens e mulheres apresentam níveis variados de socialização e habilidades sociais, como também apresentam padrões de associações diferenciados entre essas variáveis. Essa é uma informação de especial interesse para o entendimento dos construtos envolvidos, mas considerase necessária a ampliação da amostra para verificar se tais resultados são mantidos.

\section{Discussão}

Este trabalho analisou as relações entre habilidades sociais e socialização em estudantes universitários, partindo-se do pressuposto de que as interações sociais estabelecidas entre as pessoas são favorecidas ou dificultadas em razão das tendências de personalidade das mesmas. Do mesmo modo, as gratificações e frustrações que a pessoa recebe no contato com as demais podem afetar a organização da sua personalidade (Bueno, Oliveira \& Oliveira, 2001).

A definição de socialização adotada foi concebida no modelo dos Cinco Grandes Fatores, um dos mais recentes e utilizados no estudo da personalidade. Nesse modelo, a socialização é tida como uma dimensão da personalidade que abarca a qualidade das interações pessoais que os indivíduos apresentam.

A literatura de habilidades sociais tem apresentado sistematicamente associações com características de personalidade (Bueno, Oliveira \& Oliveira, 2001; Reis e cols., 1985; Schill, 1995; entre outros). Entretanto, especificamente com a socialização não foram encontrados trabalhos que aprofundassem suas relações considerando seus componentes, sendo esse um dos motivadores para a execução deste trabalho.

As análises iniciais feitas com as medidas obtidas de socialização e habilidades sociais indicaram algumas diferenças significativas entre os sexos dos sujeitos. Assim, as mulheres apresentaram uma maior incidência de pró-sociabilidade, socialização total, auto-afirmação na expressão de sentimentos positivos e auto-exposição a desconhecidos e situações novas. Esses resultados indicam que apresentaram uma maior tendência a expressar afetos positivos, elogiar familiares, defender alguém do grupo, além de abordar desconhecidos, pedindo-lhes favores ou fazendo-lhes perguntas, e falar em público. Também evidenciaram uma maior incidência 
de características de personalidade como amabilidade, altruísmo, cuidado com os demais, apoio emocional, bondade, prestatividade e altruísmo, além de empatia, responsividade e confiança nos demais.

No caso dos homens, evidenciaram-se resultados mais elevados no fator autocontrole da agressividade, o que sugere uma maior tendência deles reagirem adequadamente a estimulações que demandam o controle de agressividade e raiva, lidando com críticas e brincadeiras ofensivas, mas com um componente de impulsividade. Tais achados estão em consonância com alguns trabalhos da literatura que identificaram uma predisposição à sociabilidade e maior competência social em mulheres, como os de Gambrill e Richey (1975), Hollandswort e Wall (1977), Eisler, Hersen, Miller e Blanchard (1975), Hess (1975), dentre outros. Esses estudos identificaram uma maior tendência das mulheres manifestarem apreço pelos outros, indicarem mudanças de comportamento, falarem mais tempo com os demais, elogiarem, dentre outras condutas, enquanto os homens apresentaram dificuldades em expressar sentimentos, fazer pedidos ou ser assertivos. Em relação ao controle de agressividade, nenhum trabalho identificou diferenças específicas diretamente. Todavia, Rose e Tyron (1979) sugeriram que as condutas assertivas femininas tendem a ser percebidas como mais agressivas que as masculinas. Apesar disso, a diferença de sexo segue sendo um tema controvertido na literatura, uma vez que nem todos os trabalhos identificaram esse aspecto, valendo a pena ser mais estudado (Schroeder \& Rakos, 1983).

Com base nas diferenças identificadas, foram realizadas análises de correlação em razão do sexo. Sintetizando as análises correlacionais iniciais (com toda a amostra), evidenciou-se uma tendência dos universitários mais altruístas e preocupados com os demais, empáticos e atenciosos expressarem afetos positivos. Além disso, indivíduos caracterizados como confiantes nos demais menos se afirmaram em defesa de seus direitos, manifestando pouca assertividade e maior controle da agressividade em situações adversas.

Finalmente, pôde-se referir, pelos dados encontrados, que quanto mais habilidade social os universitários manifestaram, mais tenderam a ser atenciosos, compreensivos e empáticos, agradáveis com os demais, sendo essas as características de personalidade desses indivíduos. Essa tendência independeu do sexo, quando analisados separadamente, embora as mulheres mais hábeis socialmente também tenham manifestado um maior autocontrole de agressividade em situações desagradáveis.

Os homens com características de socialização mais evidentes foram aqueles que manifestaram mais sentimentos positivos aos demais, sendo essa a única tendência do sexo masculino. As mulheres, por sua vez, mantiveram as associações já identificadas com a amostra como um todo, obtendo mais variáveis de socialização e habilidades sociais associadas do que os homens, além de coeficientes mais elevados que no geral. Esse aspecto suscita alguns questionamentos como até que ponto as diferenças de sexo nas habilidades sociais identificadas em certos trabalhos na literatura ocorreriam se fossem controladas as características de personalidade desses sujeitos? Entretanto, há que se considerar que os coeficientes de correlação foram relativamente baixos, o que indicou pouca variância comum entre essas variáveis. Esses dados convidam a novas investigações.

No trabalho de Bueno, Oliveira e Oliveira (2001), os autores identificaram associações significativas entre socialização e expressão de afetos positivos e equilíbrio emocional, assim como autocontrole da agressividade. Esses dados também foram identificados e corroborados neste trabalho, já que evidencaram-se as mesmas associações com o total de socialização. Considerando que no trabalho de Bueno, Oliveira e Oliveira (2001) os autores empregaram uma lista de adjetivos descritores da personalidade, somente evidenciaram as associações no geral. No presente estudo, aprofundaram-se as análises, indicando quais características específicas do traço socialização estariam associadas às habilidades sociais, o que representou um avanço.

Conhecendo as relações das características de personalidade e os comportamentos socialmente hábeis, poder-se-ia pensar em novas formas de intervenção clínica nessa área, já que mudanças produzidas em um desses aspectos poderia afetar o outro. Este tipo de informação deve ser mais bem investigado.

Resta mencionar que os dados em questão, enquanto em consonância com a literatura de modo geral, podem ser considerados como evidências de validade para os instrumentos em questão por relação com outras variáveis. Um outro critério que talvez fosse interessante ser estabelecido em relação a ambos os instrumentos, enquanto medida da qualidade das relações sociais, seria a medida sociométrica, ficando a sugestão de novas investigações.

\section{Referências}

Bellack, A. S. \& Morrison, R. L. (1982). Interpersonal dysfunction. Em A. S. Bellack, M. Hersen \& A. E. Kazdin (Comps.). International handbook of behavior modification and therapy, Nova Iorque, Plenum.

Bueno, J. M. H., Oliveira, S. M. S. S. \& Oliveira, J. C. S. (2001). Um estudo correlacional entre habilidades 
sociais e tracos de personalidade com universitários. PsicoUSF, 6, 31-38.

Caballo, V. E. (2003). Manual de avaliação e treinamento das habilidades sociais. São Paulo: Santos Editora.

Del Prette, A., Del Prette, Z. A. P, \& Barreto, M. C. M. (1999). Habilidades sociales en la formación del psicólogo: análisis de un programa de intervención. Psicologia Conductual, 7(1), 27-47.

Del Prette, Z. A. P. \& Del Prette, A. (2001). Inventário de habilidades sociais: manual de aplicação, apuração $e$ interpretação. São Paulo: Casa do Psicólogo.

Del Prette, Z. A. P., Del Prette, A. \& Barreto, M. C. M. (1998). Análise de um inventário de habilidades sociais (IHS) em uma amostra de universitários, Psicologia: Teoria e Pesquisa, 14(3), 219-228.

Digman, J. M. (1990). Personality structure: The emergence of the Five-Factor Model. Annual Review of Psychology, 41, 417-440.

Eisler, R. M., Hersen, M., Miller, P. M. \& Blanchard, E. B. (1975). Situational determinants of assertive behaviors. Journal of Consulting and Clinical Psychology, 43(3), 330-340.

Facto, D. C. \& Schilmoeller, G. L. (1983). Social skill training of preschool children. Cbild Study Journal, 13(1), 41-56.

Gambrill, E. D. \& Richey, C. A. (1975). An assertion inventory for use in assessment and research. Behavior Therapy, 6, 550-561.

Hess, E. H. (1975). The role of pupil size in communication. Scientific American, 233, 110-119.

Hollandsworth, J. G. \& Wall, K. (1977). Sex differences in assertive behavior: An empirical investigation. Journal of Counseling Psychology, 24, 217-222.

Hutz, C. S., Nunes, C. H. S. S., Silveira, A. D., Serra, J., Anton, M. \& Wieczorek, L. S. (1998). O desenvolvimento de marcadores para a avaliação da personalidade no modelos dos Cinco Grandes Fatores. Psicologia: Reflexão e Crítica, 11, 395-409.

Kontos, S., Hsu, H. C. \& Dunn, L. (1994). Children's cognitive and social competence in child care centers and family day-care homes. Journal of Applied Developmental Psychology, 15(3), 387-411.

Lazarus, A. A. (1973). On assertive behavior: A brief note. Behavior Therapy, 4, 697-699.

Nunes, C. H. S. S. \& Hutz, C. S. (2002). O modelo dos Cinco Grandes Fatores de Personalidade. Em R.
Primi (Ed.). Temas em avaliação psicológica (pp. 40-49). Campinas, SP: IBAP.

Nunes, C. H. S. S. \& Hutz, C. S. (2007a). Construção da validação da escala fatorial de socialização no modelo dos Cinco Grandes Fatores de Personalidade. Psicologia: Reflexão e Crítica, 20(1), 20-25.

Nunes, C. H. S. S. \& Hutz, C. S. (2007b). Escala Fatorial de Socialização - manual técnico. São Paulo: Casa do Psicólogo.

Nunes, C. H. S. S., Nunes, M. F. O. \& Hutz, C. S. (2006). Uso conjunto de escalas de personalidade e entrevista para identificação de indicadores de transtorno anti-social. Avaliação Psicológica, 5(2), 171178.

Penn, D. L. \& Mueser, K. T. (1995). Cognitivebehavioral treatment of schizophrenia. Psicología Conductual, 3, 5-34.

Rathus, S. A. (1975). Principles and practices of assertive training: An eclectic overview. The Counseling Psychologist, 5, 9-20.

Reis, H. T., Wheeler, L., Kernis, M. H., Spiegel, N. \& Nezlek, J. (1985). On specificity in the impact of social participation on physical and psychological health. Journal of Personality and Social Psychology, 48(2), 456-471.

Rose, Y. J. \& Tryon, W. W. (1979). Judgments of assertive behavior as a function of speech loudness, latency, content, gestures, inflection and sex. Behavior Modification, 3, 112-123.

Schill, T. (1995). Social skills of persons with selfdefeating personality. Psychological Reports, 77(2), 632634.

Schroeder, H. E. \& Rakos, R. F. (1983). The identification and assessment of social skills. Em R. Ellis \& D. Whittington (Comps.). New directions in social skill training. Londres: Croom Helm.

Widiger, T. A., Trull, T. J., Clarkin, J. F., Sanderson, C. \& Costa, P. T. (2002). A description of the DSM-IV personality disorders with the five-factor model of personality. Em P. T. Costa \& T. A. Widiger (Eds.). Personality disorders and the Five-Factor Model of Personality (2 ${ }^{\mathrm{a}}$ ed., pp. 89-102). Washington, DC: American Psychological Association.

Recebido em outubro de 2007 Reformulado em janeiro de 2008 Aprovado em maio de 2008 
Sobre os autores:

Daniel Bartholomeu é psicólogo formado pela Universidade São Francisco, tendo realizado seu mestrado nessa mesma instituição. Atua como docente na Faculdade Politécnica de Jundiaí e no Centro Universitário Salesiano de Americana.

Carlos Henrique Sancineto da Silva Nunes é psicólogo formado pela Universidade Federal do Rio Grande do Sul, tendo realizado mestrado e doutorado na mesma instituição. Colaborador do Laboratório de Mensuração da Universidade Federal do Rio Grande do Sul e do Laboratório de Avaliação Psicológica e Educacional da Universidade São Francisco, atua na área de desenvolvimento / adaptação, validação e normatização de testes para a avaliação da personalidade e inteligência.

Afonso Antonio Machado é formado pela PUC em Educação Física, tendo realizado seu doutorado e mestrado em Educação, pela Universidade Estadual de Campinas. É livre-docente pela Universidade Estadual Paulista Júlio de Mesquita Filho, docente da Graduação em Educação Física na Escola Superior de Educação Física de Jundiaí, no Instituto Superior de Educação Uirapuru (Sorocaba) e professor adjunto da Universidade Estadual Paulista Júlio de Mesquita Filho, onde ministra aulas na graduação e pós-graduação. 